\title{
COMMENTARY
}

\section{On the concept of a psychrophile}

\author{
Ricardo Cavicchioli
}

The ISME Journal (2016) 10, 793-795; doi:10.1038/ ismej.2015.160; published online 15 September 2015

Cold environments dominate the Earth's biosphere and are colonized by abundant and diverse microorganisms that play potentially critical roles in global biogeochemical cycles-so clearly they are important, but do we have a good concept of what they are?

Whether microorganisms are Bacteria, Archaea, Eucarya or viruses, if they grow in naturally cold environments a good assumption is that they are cold adapted and 'like' the cold. The term 'psychrophile' reflects this-from Greek, psukhros meaning 'cold' and philein, 'to love'. However, when contemplating the typical traits of psychrophiles, clearly temperature is not the only factor that controls their existence. As with all environmental systems, the abundance of individual taxa and the ecology of the system is determined by the lifestyle (for example, trophism) of each taxon, their responses to all biotic and abiotic parameters that define the system (that is, environmental selection) and biogeographic constraints (that is, the effects of physical barriers and distance on dispersal and colonization).

Problems with the concept of a psychrophile have arisen because of the tendency for many in the field to use temperature-dependent growth rate as a measure for assessing how well adapted a microorganism is to the cold (see discussion in Brenchley, 1996; Feller and Gerday, 2003; Bakermans and Nealson, 2004; Cavicchioli and Siddiqui, 2004; Goodchild et al., 2004; Cavicchioli, 2006; Ting et al., 2010; Williams et al., 2011; Lauro et al., 2011a). This is a false guide because, when temperature increases, enzyme reaction rates increase as a result of the kinetic effect of heat, and microbial growth rates increase until some process in the cell becomes thermally compromised. The upper growth temperature $\left(T_{\max }\right)$ for a microorganism simply defines the highest temperature it can possibly tolerate. Most isolates from cold environments can grow in the laboratory at temperatures well above what they would typically encounter in the environment. As such, a psychrophile that can cope with a relatively high $T_{\max }$ (for example, $30^{\circ} \mathrm{C}$ ) could conceivably be considered 'mesotolerant'. Given this simple logic, the question must be raised of why terms with essentially an opposite connotation are often used: 'psychrotolerant', 'psychrotroph' or 'facultative psychrophile'.
Farrell and Rose (1967) noted that the term 'psychrophile' had been used since the early 1900s, and that as mesophiles and thermophiles were defined on the basis of their optimum temperatures, it seemed appropriate back then to do the same for psychrophiles. They highlighted limitations of this approach and noted the difficulty microbiologists had in being able to agree on a precise definition and terms used for a psychrophile. This issue was also described by Brenchley (1996) who noted that research in the 1960s and 1970s continued to generate debate about the defining characteristics of psychrophiles; for example, a psychrophile being defined as an organism unable to grow at temperatures $>20^{\circ} \mathrm{C}$ versus one that must be able to grow at $\leqslant 5^{\circ} \mathrm{C}$ in contrast to a mesophile with best growth at $37^{\circ} \mathrm{C}$. The literature now contains a large number of terms and definitions, most of which revolve erroneously around arbitrary limits for the temperature at which an organism grows fastest (temperature 'optimum', $T_{\mathrm{opt}}$ ) and/or $T_{\max }$.

So why has the issue arisen and persisted? The problem seems to stem from concepts learned from classical microbiology, particularly laboratory studies of enteric bacteria, and the notion that fast growth means competitiveness and fastest growth is therefore optimal-hence the term, $T_{\text {opt }}$. The concept that fast growth is best poses serious issues when considering environmental microorganisms. For example, a typical marine oligotrophic microorganism grows relatively slowly and consistently even at very low nutrient concentrations, but it cannot compete with a copiotroph when nutrients are abundant as the growth rate of the copiotroph will be much higher (Ting et al., 2010). Based upon growth in rich laboratory medium, the copiotroph (analogous to a hare) will be predicted to be the winner, yet in the bulk of the marine environment, the oligotroph (analogous to the tortoise) is indeed the winner. I use this analogy purposefully to avoid the core issue of temperature, and highlight the inherent problems with the use of laboratorydetermined growth rates for judging how well adapted environmental microorganisms are to their environments.

Focusing on specific examples related to the cold, consider that based on laboratory studies, the $T_{\text {opt }}$ and $T_{\max }$ for Methanococcoides burtonii are $23^{\circ} \mathrm{C}$ and $28^{\circ} \mathrm{C}$, and for Methanogenium frigidum $15^{\circ} \mathrm{C}$ and $18^{\circ} \mathrm{C}$, respectively (Cavicchioli, 2006). If $T_{\mathrm{opt}}$ and $T_{\max }$ were useful measures of cold 
adaptation, $M$. frigidum would be predicted to be better adapted. However, M. burtonii grows faster at lake temperatures than $M$. frigidum, so even using growth rate as a measure of fitness, here $T_{\text {opt }}$ and $T_{\max }$ are misleading. From an ecological standpoint, this question is even far more complicated. Consider that both methanogens were isolated from Ace Lake, Antarctica, and each uses different carbon and energy sources (methylated substrates vs $\mathrm{H}_{2}: \mathrm{CO}_{2}$ ). Based upon laboratory temperature- dependent growth rate studies, which would be predicted to be dominant? Clearly many factors would need to be considered, substrate concentrations being just one of them. It turns out that despite the waters of Ace Lake being methane saturated and therefore methanogens predicted to be abundant and thriving, metagenome analyses revealed that methanogens as a whole have a very small representation in the lake (Lauro et al., 2011b). The example illustrates the difficulty in trying to infer how well adapted and ecologically important a microorganism is based on laboratory, temperature-dependent growth rate measurements of pure isolates.

To take further examples, in northern hemisphere cold marine waters $\left(4-10^{\circ} \mathrm{C}\right)$, Sphingopyxis alaskensis can be a numerically dominant member of the population (Ting et al., 2010). In the southern hemisphere Antarctic waters of Deep Lake, temperature drops to $-20^{\circ} \mathrm{C}$ in winter and haloarchaea dominate, with one species alone representing $\sim 40 \%$ of the entire lake population (DeMaere et al., 2013). However, despite the competitiveness of these microorganisms in different global cold environments, in the laboratory it is challenging to grow any of them at $\leqslant 4{ }^{\circ} \mathrm{C}$, and the haloarchaea can grow at temperatures $>30^{\circ} \mathrm{C}$ and $S$. alaskensis at $45^{\circ} \mathrm{C}$. Imagine how wrong we would be if $T_{\mathrm{opt}}$ or $T_{\max }$ were used to infer how well adapted these ecologically relevant microorganisms are to the cold, and if labels such as psychrotolerant were used to categorize them.

Beyond the ecological naivety of using temperature-dependent growth rate to infer how well adapted an organism is to the cold, a wide variety of studies examining the molecular and physiological responses of psychrophiles reveal that growth at ' $T_{\text {opt }}$ ' can be stressful. This includes assessments of growth yield, viability, level of enzyme secretion, protein synthesis, membrane permeability and stress markers (see discussion and papers cited in Brenchley, 1996; Feller and Gerday, 2003; Bakermans and Nealson, 2004; Cavicchioli and Siddiqui, 2004; Goodchild et al., 2004; Cavicchioli, 2006; Ting et al., 2010; Williams et al., 2011; Lauro et al., 2011a). Functional 'omic' studies canvass changes in global gene expression and provide a broad level of insight into cellular responses. Molecular markers of heat stress were identified for both S. alaskensis (Ting et al., 2010) and M. burtonii (Williams et al., 2011) when grown at elevated temperatures. By comparing proteome profiles across the full growth temperature range of $M$. burtonii $\left(-2^{\circ} \mathrm{C}\right.$ to $\left.28^{\circ} \mathrm{C}\right)$, heat stress was shown to occur at $23^{\circ} \mathrm{C}\left(T_{\text {opt }}\right)$ and $28^{\circ} \mathrm{C}\left(T_{\text {max }}\right)$, cold stress at $-2{ }^{\circ} \mathrm{C}\left(T_{\min }\right)$ and cells to be 'happily' growing at 1-16 ${ }^{\circ} \mathrm{C}$ (Williams et al., 2011). For S. alaskensis, two sets of protein folding systems were found to be differentially regulated, with one upregulated in the cold and inferred to play a specific role in cold adaptation (Ting et al., 2010).

It was also inferred from transcriptomic studies that a permafrost Psychrobacter sp. that can grow at temperatures from $-10^{\circ} \mathrm{C}$ to $\sim 30^{\circ} \mathrm{C}$ had the capacity to shift from a well-functioning, relatively fastgrowing state between 6 and $22^{\circ} \mathrm{C}$ to a resource efficiency state at $<4{ }^{\circ} \mathrm{C}$ (Bergholtz et al., 2009). In a separate study, the critical temperature $\left(T_{\text {critical }}\right.$; the temperature below $T_{\text {opt }}$ in an Arrhenius plot where the slope changes) was shown to associate with generating maximum growth yield (Bakermans and Nealson, 2004). This highlights that temperaturedependent growth rate-related characteristics other than $T_{\text {opt }}$ and $T_{\max }$ may offer insight into the physiology and adaptive responses of psychrophiles. The study argued that at low temperature it was likely to be beneficial for psychrophiles to maximize growth yield, rather than growth rate (Bakermans and Nealson, 2004). To date, only few omic studies have been performed to effectively assess the effects of temperature on psychrophiles. As such, it is presently not sensible to attempt to infer general principles that may explain the capacity for many psychrophiles to grow at temperatures well above natural environmental temperatures. However, the upshot from these studies clearly illustrates that psychrophiles can be genetically geared to cope with heat and the stress that it causes, while also having the genetic capacity to function effectively in the cold.

Finally, and interestingly so, valuable concepts about cold adaptation can in fact be learned from some studies of Escherichia coli. Compared with wild type, a temperature-sensitive mutant that has a genetic defect and can no longer grow at $42^{\circ} \mathrm{C}$ (that is, high temperature) does not have a better capacity to grow at low temperature. This illustrates clearly that $T_{\max }$ has no bearing on the capacity to grow and compete in the cold. In a rather confounding and therefore valuable study, E. coli that is typically regarded as not being capable of growth below $\sim 8^{\circ} \mathrm{C}$ was immersed for a prolonged period in Antarctic sea water and found to then form colonies on plates at $-1.8^{\circ} \mathrm{C}$ but no longer at $37^{\circ} \mathrm{C}$ (Smith et al., 1994). Although the study was performed to assess the survivability of pathogens in sewage dumped into Antarctic sea water, it provokes contemplation about evolutionary paths to cold adaptation, perceptions of requirements for growing in the cold and even challenging our capacity to pigeon-hole microbes into terms we like to use (that is, is E. coli a mesophile?).

Terminology is important if it conveys concepts and is therefore educationally meaningful-a point that has been made clear with regard to 
the inappropriate use of the word 'prokaryote' (Pace, 2006). Propagating misused terms is akin to 'gene rot' for gene misannotations, and therefore needs reckoning. This was discussed at the Workshop on Cold Adaptations of Aquatic Microorganisms, The Max Planck Institute for Marine Microbiology, Bremen, Germany, 2003, leading to terminology proposed for psychrophiles described by Feller and Gerday (2003). Based on the microbial ecology terms derived from Shelford's law of tolerance, 'steno-' and 'eury-' describe a narrow or wide tolerance to an environmental determinant, respectively (Atlas and Bartha, 1998), and the terms 'eurypsychrophile' and 'stenopsychrophile' have been used (for example, Bakermans and Nealson, 2004; Cavicchioli and Siddiqui, 2004; Cavicchioli, 2006). Because these are accepted ecological terms, and the concept of a psychrophile needs to take into account the environmental setting, these terms have some value. However, it is likely that there is a continuum in the temperature range that microbial life has adapted to, and hence employing terms to subdivide psychrophiles is of questionable value. Above all, temperature-dependent assessments of growth rates provide misconceptions about how well adapted microorganisms are to their native cold habitats. I therefore suggest that the singular term 'psychrophile' is both appropriate and sufficient for describing microbes indigenous to cold environments. This contrasts with the terms 'psychrotolerant', 'psychrotroph' and 'facultative psychrophile' that defy logic.

\section{Conflict of Interest}

The author declares no conflict of interest.

R Cavicchioli School of Biotechnology and Biomolecular Sciences, The University of New South Wales, Sydney, New South Wales, Australia E-mail: r.cavicchioli@unsw.edu.au

\section{References}

Atlas RM, Bartha R. (1998). Microbial Ecology: Fundamentals and Applications, 4th edn. Benjamin/Cummings Science Publishing: Menlo Park, CA.
Bakermans C, Nealson KH. (2004). Relationship of critical temperature to macromolecular synthesis and growth yield in Psychrobacter cryopegella. J Bacteriol 186: 2340-2345.

Bergholz PW, Bakermans C, Tiedje JM. (2009). Psychrobacter arcticus 273-4 uses resource efficiency and molecular motion adaptations for subzero temperature growth. J Bacteriol 191: 2340-2352.

Brenchley JE. (1996). Psychrophilic microorganisms and their cold-active enzymes. J Indust Microbiol 17: 432-437.

Cavicchioli R. (2006). Cold adapted Archaea. Nat Rev Microbiol 4: 331-343.

Cavicchioli R, Siddiqui KS. (2004). Cold adapted enzymes. In: Pandey A, Webb C, Soccol CR, Larroche C (eds) Enzyme Technology, Chapter 31. Asiatech Publishers, Inc.: New Delhi, India, pp 615-638.

DeMaere MZ, Williams TJ, Allen MA, Brown MV, Gibson JAE, Rich J et al. (2013). High level of intergenera gene exchange shapes the evolution of haloarchaea in an isolated Antarctic lake. Proc Natl Acad Sci USA 110: 16939-16944.

Farrell J, Rose A. (1967). Temperature effects on microorganisms. Annu Rev Microbiol 21: 101-120.

Feller G, Gerday C. (2003). Psychrophilic enzymes: hot topics in cold adaptation. Nat Rev Microbiol 1: 200-208.

Goodchild A, Saunders NFW, Ertan H, Raftery M, Guilhaus M, Curmi PMG. (2004). A proteomic determination of cold adaptation in the Antarctic archaeon, Methanococcoides burtonii. Mol Microbiol 53: 309-321.

Lauro FM, Allen M, Wilkins D, Williams TJ, Cavicchioli R. (2011a). Genetics, genomics and evolution of psychrophiles. In: Horikoshi K (ed) Extremophiles Handbook, Chapter 6.6. Springer: Japan, pp 865-890.

Lauro FM, DeMaere MZ, Yau S, Brown M, Ng C, Wilkins D et al. (2011b). An integrative study of a meromictic lake ecosystem in Antarctica. ISME J 5: 879-895.

Pace NR. (2006). Time for a change. Nature 441: 289.

Smith JJ, Howington JP, McFeters GA. (1994). Survival, physiological response and recovery of enteric bacteria exposed to a polar marine environment. Appl Environ Microbiol 60: 2977-2984.

Ting L, Williams TJ, Cowley MJ, Lauro FM, Guilhaus M, Raftery MJ, Cavicchioli R. (2010). Cold adaptation in the marine bacterium, Sphingopyxis alaskensis assessed using quantitative proteomics. Environ Microbiol 12: 2658-2676.

Williams TJ, Lauro FM, Ertan H, Burg DW, Poljak A, Raftery MJ, Cavicchioli R. (2011). Defining the response of a microorganism to growth temperature that spans its full growth temperature range $\left(-2^{\circ} \mathrm{C}\right.$ to $28^{\circ} \mathrm{C}$ ) using multiplex quantitative proteomics. Environ Microbiol 13: 2186-2203. 